\title{
Gender differences in the use of mental health services in a Barcelona area
}

\author{
Judith Usall, PhD MD*,** \\ Raquel Iniesta** \\ Susana Ochoa, $\mathrm{PhD}^{\star, \star *}$ \\ Victoria Villalta, $\mathrm{PhD}^{\star \star}$ \\ David Suárez, $\mathrm{PhD}^{\star \star \star}$ \\ Marcelo Pezzimenti, MD* \\ Victoria Moneta** \\ Marisol Torres* \\ Francisco Mochón* \\ Jesús Millán*
}

* Parc Sanitari Sant Joan de Déu

** Fundació Sant Joan de Déu, Instituto de Salud Carlos III, Centro de Investigación en Red de Salud Mental (CIBERSAM)

*** Unitat d'Epidemiologia i Avaluació, Fundació Parc Taulí, Universitat Autònoma de Barcelona, Sabadell

SPAIN

\begin{abstract}
Background and Objectives: The exploration of the use of specialised mental health services and the prevalence of mental disorders recorded by these services is important when planning and adapting the various mental health services to real users' needs. The fact of being a woman has repeatedly proved to be a predicting factor for higher service use and this could imply than such needs may vary according to gender. The objectives of our study are: to analyse the attended prevalence in both out-patient and hospital services data as per diagnoses according to gender, and to analyse the use of hospital care services with respect to diagnoses according to gender.

Methods: The sample for this observational and retrospective study $(\mathrm{n}=65,465)$ is comprised of everyone who visited any of the Sant Joan de Déu-SSM mental health services between 2002 and 2007. Main measures: total number of consultations, and number and length of hospitalisations.

Results: Women presented higher attended prevalence. Men show a higher risk of a first hospitalisation and longer length of admissions. Among the group of admitted patients, the number of women is higher. With regard to diagnosis, gender influences the attended prevalence. Regarding hospitalisation, we find differences in patients with schizophrenia and other mood disorders.

Conclusions: The main result is that women have a higher attended prevalence of mental disorders than men. In the total sample, women have a higher number of hospitalisa-
\end{abstract}


tions although men have a higher risk of a first hospitalisation and their stays prove to be longer. When taking diagnosis into account, gender differences are greater in attended prevalence than in number and length of hospitalisations.

Received: 14 October 2010

Revised: 7 June 2011

Accepted: 17 November 2011

\section{Introduction}

The fact of being a woman has repeatedly proved to be a predicting factor of higher service use ${ }^{1-3}$. Studies on prevalence in the general population show that women have twice the risk of suffering mood disorders-especially dysthymia-throughout their lives ${ }^{4-6}$. They also have twice the risk of suffering anxiety disorders, except for obsessive-compulsive disorder, which seems to be more prevalent in $\operatorname{men}^{5,6}$. On the other hand, women are between 2 and 5 times less likely to suffer alcohol abuse disorders or psychoactive substance abuse disorders ${ }^{4,5}$. Eating disorders are more prevalent in women ${ }^{5}$. Furthermore, women show greater comorbidity than men ${ }^{5}$.

Other studies find gender differences in the way people seek health care. Although both men and women appear to respond similarly in seeking professional care when they suffer a serious condition, women tend to seek professional care more frequently than men when they suffer minor health problems ${ }^{7}$.

In summary, we find that many disorders are far more prevalent in women than in $\mathrm{men}^{8}$ in the general population, although no studies assessing psychiatric pathology prevalence according to gender in specialised mental health services have been found. Moreover, various studies prove that women are more likely to seek help from specialised mental health services than men, at similar levels of discomfort ${ }^{9}$.

With respect to hospital care service use, we have not found any study that analyses hospitalisation using gender as the principal variable.

To date, most studies show that women are more likely to use mental health services (consultation and drug consumption use) than men although the patterns of service use should be periodically revised as they are subject to possible changes in the organization of mental health services ${ }^{10}$.

The exploration of the use of specialised mental health services and the prevalence of mental disorders recorded by these services is important when planning and adapting the various mental health services to real users' needs. Such needs may vary according to gender.

The two objectives of our study are: to analyse the attended prevalence in both outpatient and hospital services data with regard to diagnoses according to gender; and to analyse the use of hospital care services with respect to diagnoses according to gender. 


\section{Method}

This is an observational and retrospective study based on the review of data recorded in the computerised clinical records of Sant Joan de Déu-Mental Health Services (SJD-SSM).

\section{Subjects of study}

The sample of the study is comprised of everyone who visited any SJD-SSM mental health service between 2002 and 2007.

The institution has maintained computerised clinical records since 2001 which allow access to data on the patients who have visited the health services. The Sant Joan de Déu-SSM mental health care centres network is very wide and includes hospital and out-patient care in Barcelona and the metropolitan area (with total coverage of a population of 800,000$)$.

\section{Variables}

A number of variables were collected from the clinical records, transformed and recoded for the objectives of the study:

- Socio-demographic characteristics of the patients: gender and age.

- Diagnosis. For people with more than one diagnosis, the last diagnosis determined by the reference therapist (according to DSM-IV-R criteria) has been considered.

- Years of treatment in Sant Joan de Déu-SSM: For each patient, time elapsed between the first visit registered in the Clinical Record and the last or the closing date of the study.

- Use of services: Number of admissions to hospital care services and total number of days of admission in each service.
From these variables, data were recoded to obtain the attended prevalence, that is, an an estimate of the number of people who sought medical assistance for their health problems at the SJD-SSM mental health network (outpatients' and hospital services data); the total admissions in all inpatients' services, and the total length of stay of these admissions.

\section{Ethical aspects}

People attended at SJD-SSM sign a consent agreement stating that all data in their clinical record is confidential and is subject to the data protection law currently in force. The study was approved by the Hospital Sant Joan de Déu Ethical Committee.

\section{Statistical analysis}

Bivariate associations between gender and covariates age and years of treatment were tested with t-Student and $\mathrm{Chi}^{2}$ tests. Proportions of men and women attended at hospital were compared by means of test $\mathrm{z}$. Adjusted Odds Ratios (OR) were used to describe the risk of having at least one admission during the study period. To summarise the risk, according to gender, of a patient adding a new admission and the risk of adding a new hospitalised day for patients who have had at least one admission to any of the hospital services, adjusted Risk Ratios (RR) were obtained through Poisson and Negative Binomial regressions. Given the imbalance of data and the possible dependence and recurrence between number and length of admissions, the dispersion of data was studied in order to avoid an extraPoisson variance effect ${ }^{11}$. Thus, depending on whether the overdispersion proved to be significant, the variable was modelled according to a Binomial Negative or a Poisson 
regression model. Specifications about the use of each model will be found as a footnote in the table of results. The category of reference for all risk measures are women. Since the age of the patients and the years of treatment could affect the behaviour of a patient regarding hospitalisations, all models were adjusted by these two variables. Other covariates of interest were discarded from the analysis due to a high percentage of missing values. Confidence intervals were calculated at $95 \%$. Analyses were carried out with R 2.8.1.

\section{Results}

The total sample of patients collected from the medical record was 65,465: 39,479 women and 25,986 men. The average age for women was 50 years (SD 17) and 48 (SD 16) years for men. There is a significant association between gender and age $(\mathrm{p}<0.001)$.

The average years of treatment for women was 6.68 years (SD 4.29) and 7.24 (SD 6.36) for men. There is also a significant association between gender and years of treatment $(\mathrm{p}<0.001)$.

Women have a higher attended prevalence than men $(\mathrm{p}<0.001)$. When analyzing by diagnosis, only social phobia, obsessive compulsive disorder, factitious disorder, sleep disorder and avoidant personality disorder had the same distribution in male and female samples (see table 1).

Table 2 shows results on the risk of being admitted to hospital by gender during the 5year period of the study. Regardless of the diagnoses, the risk of being admitted to the hospital for the first time is twice as high for men as for women $(\mathrm{p}<0.001)$. Taking diagnoses into account, the odds ratio shows that women have 1.75 times more risk of being inpatients with an impulse-control disorder $(\mathrm{p}<0.05)$. On the other hand, men have a higher probability of being admitted to a mental health hospital if they are diagnosed with: a disorder usually first diagnosed in infancy $(\mathrm{p}<0.05)$, cognitive disorder $(\mathrm{p}<0.001)$, schizophrenia $(\mathrm{p}<0.01)$, other mood disorders $(\mathrm{p}<0.001)$, anxiety disorder NOS $(\mathrm{p}<0.05)$, adjustment disorders $(\mathrm{p}<0.001)$, and personality disorder NOS $(\mathrm{p}<0.05)$. No gender differences were found in the probability of being admitted to hospital in other diagnoses.

Only $13.6 \%$ of included patients have been admitted to hospital. The mean of admissions per year is: 0.47 (SD 0.71) for women and 0.46 (SD 0.62) for men. This difference is statistically significant (p.val<0.001).

Table 3 shows statistically significant results, by gender, for the number of admissions to hospital and the number of days of hospitalisation for patients who were admitted at least once during the study period. In the total sample, women have a higher number of hospitalisations than men $(\mathrm{p}<0.001)$. The mean of admissions is higher than 0.50 in women who have schizophrenia, bipolar disorder, impulse-control disorder, borderline personality disorder and histrionic personality disorder. In men, the average number of admissions is higher than 0.50 in schizophrenia, obsessive-compulsive disorder, antisocial personality disorder and borderline personality disorder (results not shown in table). Women with: other mood disorders $(\mathrm{p}<0.01)$, generalised anxiety disorder $(\mathrm{p}<$ $0.001)$, and adjustment disorder $(\mathrm{p}<0.01)$ were admitted more times than men.

With regard to the number of days in hospital, by gender, for patients who have been admitted at least once, the length of stays in hospital were 15.56 (SD 39.98) days per year in the women's group and 24.63 (SD 56.87 ) days per year in the men's group 
Table 1

Prevalence of attended diagnosis by gender

$\begin{array}{lll}\text { Female } & \text { Male } & \text { Total sample }\end{array}$

\begin{tabular}{|c|c|c|c|c|c|c|c|}
\hline & $\mathrm{N}$ & $(\%)^{1}$ & $\mathrm{~N}$ & $(\%)^{1}$ & $\mathrm{~N}$ & $(\%)^{2}$ & \\
\hline Disorder Usually First Diagnosed in Infancy & 302 & (32.6) & 625 & $(67.4)$ & 927 & (1.4) & $* * *$ \\
\hline Cognitive Disorder & 721 & $(57.5)$ & 534 & $(42.5)$ & 1255 & (1.9) & $* * *$ \\
\hline Disorder Due to a Gral. Medical Condition & 105 & $(36.0)$ & 187 & $(64.0)$ & 292 & $(0.4)$ & $* * *$ \\
\hline Substance-Related Disorder & 904 & $(25.4)$ & 2662 & $(74.6)$ & 3566 & (5.4) & $* * *$ \\
\hline Schizophrenia & 1210 & $(32.2)$ & 2547 & $(67.8)$ & 3757 & (5.7) & $* * *$ \\
\hline Other Psychotic Disorders & 2017 & $(51.8)$ & 1877 & $(48.2)$ & 3894 & (5.9) & $*$ \\
\hline Bipolar Disorder & 790 & $(58.4)$ & 563 & $(41.6)$ & 1353 & $(2.1)$ & $* * *$ \\
\hline Other Mood Disorders & 11959 & (72.8) & 4472 & $(27.2)$ & 16431 & $(25.1)$ & $* * *$ \\
\hline Panic Disorder Without Agoraphobia & 1633 & $(66.7)$ & 814 & (33.3) & 2447 & (3.7) & $* * *$ \\
\hline Panic Disorder With Agoraphobia & 1327 & $(69.2)$ & 592 & $(30.8)$ & 1919 & (2.9) & $* * *$ \\
\hline Agoraphobia Without History of Panic Disorder & 102 & (72.3) & 39 & (27.7) & 141 & $(0.2)$ & $* * *$ \\
\hline Specific Phobia & 163 & $(72.8)$ & 61 & $(27.2)$ & 224 & $(0.3)$ & $* * *$ \\
\hline Social Phobia & 98 & $(49.2)$ & 101 & $(50.8)$ & 199 & $(0.3)$ & \\
\hline Obsessive-Compulsive Disorder & 431 & $(52.0)$ & 398 & $(48.0)$ & 829 & (1.3) & \\
\hline Posttraumatic Stress Disorder & 189 & $(63.6)$ & 108 & $(36.4)$ & 297 & $(0.5)$ & $* * *$ \\
\hline Acute Stress Disorder & 104 & $(58.8)$ & 73 & (41.2) & 177 & $(0.3)$ & $*$ \\
\hline Generalised Anxiety Disorder & 1668 & $(67.5)$ & 802 & $(32.5)$ & 2470 & (3.8) & $* * *$ \\
\hline Anxiety Disorder NOS & 2232 & $(60.6)$ & 1453 & $(39.4)$ & 3685 & $(5.6)$ & $* * *$ \\
\hline Somatoform Disorder & 861 & $(61.3)$ & 543 & (38.7) & 1404 & (2.1) & $* * *$ \\
\hline Factitious Disorder & 24 & $(61.5)$ & 15 & $(38.5)$ & 39 & $(0.1)$ & \\
\hline Dissociative Disorder & 97 & $(72.4)$ & 37 & $(27.6)$ & 134 & $(0.2)$ & $* * *$ \\
\hline Sexual Disorder & 82 & $(29.8)$ & 193 & $(70.2)$ & 275 & (0.4) & $* * *$ \\
\hline Eating Disorder & 774 & $(92.8)$ & 60 & $(7.2)$ & 834 & $(1.3)$ & $* * *$ \\
\hline Sleep Disorder & 135 & $(50.2)$ & 134 & $(49.8)$ & 269 & (0.4) & \\
\hline Impulse-control Disorder & 217 & $(26.4)$ & 604 & $(73.6)$ & 821 & $(1.3)$ & $* * *$ \\
\hline Adjustment Disorder & 9672 & $(66.0)$ & 4981 & $(34.0)$ & 14653 & $(22.4)$ & $* * *$ \\
\hline Paranoide Personality Disorder & 87 & $(37.2)$ & 147 & $(62.8)$ & 234 & $(0.4)$ & $* * *$ \\
\hline Schizoid Personality Disorder & 22 & $(17.6)$ & 103 & $(82.4)$ & 125 & $(0.2)$ & $* * *$ \\
\hline Schizotypal Personality Disorder & 27 & $(29.7)$ & 64 & $(70.3)$ & 91 & $(0.1)$ & $* * *$ \\
\hline Antisocial Personality Disorder & 15 & (13.0) & 100 & $(87.0)$ & 115 & $(0.2)$ & $* * *$ \\
\hline Borderline Personality Disorder & 376 & $(67.0)$ & 185 & $(33.0)$ & 561 & $(0.9)$ & $* * *$ \\
\hline Histrionic Personality Disorder & 361 & $(88.0)$ & 49 & $(12.0)$ & 410 & $(0.6)$ & $* * *$ \\
\hline Narcissistic Personality Disorder & 47 & $(40.2)$ & 70 & $(59.8)$ & 117 & $(0.2)$ & $*$ \\
\hline Avoidant Personality Disorder & 27 & $(40.9)$ & 39 & $(59.1)$ & 66 & $(0.1)$ & \\
\hline Dependent Personality Disorder & 112 & $(68.3)$ & 52 & $(31.7)$ & 164 & $(0.3)$ & $* * *$ \\
\hline Obsessive-Compulsive Personality Disorder & 51 & $(39.5)$ & 78 & $(60.5)$ & 129 & $(0.2)$ & * \\
\hline Personality Disorder NOS & 537 & $(46.3)$ & 624 & $(53.7)$ & 1161 & $(1.8)$ & $*$ \\
\hline Total & 39479 & $(60.3)$ & 25986 & (39.7) & 65465 & -100 & $* * *$ \\
\hline
\end{tabular}

Significance of comparision between male and female attended prevalence for each diagnosis.

$*$ p_value $<0.05 * *$ p_value $<0.01 * * *$ p_value $<0.001$.

${ }^{1}$ Percentage computed inside each diagnosis.

${ }^{2}$ Percentage computed over the total sample. 
Table 2

Odds ratio of being admitted to the hospital by gender

Type of mental Disorder OR $\quad 95 \%$ IC

\begin{tabular}{|c|c|c|c|c|}
\hline Disorder Usually First Diagnosed in Infancy & 1.50 & 1.02 & 2.23 & $*$ \\
\hline Cognitive Disorder & 1.60 & 1.24 & 2.06 & $* * *$ \\
\hline Disorder Due to a Gral. Medical Condition & 1.94 & 0.90 & 4.22 & \\
\hline Substance-Related Disorder & 1.15 & 0.97 & 1.36 & \\
\hline Schizophrenia & 1.25 & 1.08 & 1.44 & $* *$ \\
\hline Other Psychotic Disorders & 0.91 & 0.80 & 1.04 & \\
\hline Bipolar Disorder & 1.13 & 0.91 & 1.41 & \\
\hline Other Mood Disorders & 1.79 & 1.56 & 2.04 & $* * *$ \\
\hline Panic Disorder Without Agoraphobia & 1.12 & 0.57 & 2.23 & \\
\hline Panic Disorder With Agoraphobia & 0.67 & 0.18 & 2.43 & \\
\hline Agoraphobia Without History of Panic Disorder & 4.49 & 0.23 & 86.34 & \\
\hline Specific Phobia & 1.46 & 0.12 & 17.34 & \\
\hline Social Phobia & 1.09 & 0.07 & 18.25 & \\
\hline Obsessive-Compulsive Disorder & 1.72 & 0.90 & 3.28 & \\
\hline Posttraumatic Stress Disorder & 0.55 & 0.11 & 2.87 & \\
\hline Acute Stress Disorder & 0.52 & 0.08 & 3.29 & \\
\hline Generalised Anxiety Disorder & 1.10 & 0.44 & 2.79 & \\
\hline Anxiety Disorder NOS & 1.58 & 1.01 & 2.45 & $*$ \\
\hline Somatoform Disorder & 1.00 & 0.56 & 1.77 & \\
\hline Factitious Disorder & 1.29 & 0.18 & 9.29 & \\
\hline Dissociative Disorder & 0.63 & 0.26 & 1.57 & \\
\hline Eating Disorder & 0.93 & 0.12 & 7.39 & \\
\hline Impulse-control Disorder & 0.57 & 0.37 & 0.90 & $*$ \\
\hline Adjustment Disorder & 1.73 & 1.46 & 2.04 & $* * *$ \\
\hline Personality Disorder paranoide & 2.02 & 0.97 & 4.19 & \\
\hline Schizoid Personality Disorder & 3.19 & 0.39 & 26.04 & \\
\hline Schizotypal Personality Disorder & 0.63 & 0.24 & 1.70 & \\
\hline Antisocial Personality Disorder & 1.23 & 0.33 & 4.60 & \\
\hline Borderline Personality Disorder & 0.85 & 0.58 & 1.23 & \\
\hline Histrionic Personality Disorder & 0.66 & 0.25 & 1.73 & \\
\hline Narcissistic Personality Disorder & 5.03 & 0.59 & 42.62 & \\
\hline Dependent Personality Disorder & 0.29 & 0.05 & 1.58 & \\
\hline Obsessive-Compulsive Personality Disorder & 0.34 & 0.04 & 3.02 & \\
\hline Personality Disorder NOS & 1.47 & 1.09 & 1.99 & $*$ \\
\hline Total & 2.14 & 2.04 & 2.24 & $* * *$ \\
\hline
\end{tabular}

$*$ p_value $<0.05 ; * *$ p_value $<0.01 ; * * *$ p_value $<0.001$.

Women are the reference category. 
$(\mathrm{p}<0.001)$. When distinguishing by diagnosis, women and men with disorders diagnosed in infancy or with impulse-control disorder were admitted for more than 50 days to mental health hospital services. Men were admitted for more days in hospital than women in the case of adjustment disor$\operatorname{der}(\mathrm{p}<0.001)($ table 3$)$.

Table 3

Number of admissions and days in hospital in patients who have been admitted at least one time by gender

Female

Male

\begin{tabular}{|c|c|c|c|c|c|c|c|}
\hline Number of admissions & $\mathrm{N}$ patients & $\begin{array}{c}\text { Annual } \\
\text { mean(SD) }\end{array}$ & $\mathrm{N}$ patients & $\begin{array}{c}\text { Annual } \\
\text { mean(SD) }\end{array}$ & $\mathrm{RR}$ & $95 \% \mathrm{CI}$ & \\
\hline Other Mood Disorders & 625 & $0.38(0.49)$ & 392 & $0.30(0.27)$ & 0.80 & $(0.70-0.93)$ & $\dagger * *$ \\
\hline Generalised Anxiety Disorder & 13 & $0.45(0.67)$ & 7 & $0.23(0.08)$ & 0.23 & $(0.10-0.52)$ & $\ddagger * * *$ \\
\hline Adjustment Disorder & 317 & $0.35(0.38)$ & 272 & $0.28(0.24)$ & 0.81 & $(0.70-0.94)$ & $\dagger * *$ \\
\hline Total sample informed & 3803 & $0.47(0.71)$ & 5091 & $0.46(0.62)$ & 0.89 & $(0.84-0.95)$ & $\ddagger * * *$ \\
\hline \multicolumn{8}{|l|}{ Number of days } \\
\hline Adjustment Disorder & 215 & $4.82(8.15)$ & 159 & $8.29(28.32)$ & 1.83 & $(1.05-3.16)$ & $\dagger *$ \\
\hline Total sample informed & $2345 \quad 1$ & $15.56(39.98)$ & 2767 & $24.63(56.87)$ & 1.30 & $(1.14-1.48)$ & $\dagger * * *$ \\
\hline
\end{tabular}

RR of adding a new addmission or a new day of hospitalisation during the study period for patients who have been admitted at least once, regarding gender, adjusted by age and years of treatment.

Regression models chosen in accordance with overdispersion parameter for number of admissions in each diagnosis:

$\dagger$ Overdispersion significantly different of 0 , binomial negative regression performed.

$\ddagger$ Overdispersion non-singnificantly different from 0 , poisson regression performed.

Women are the reference category. Only significant results are shown. ${ }^{*}$ p_value $<0.05 * *$ p_value $<0.01$ $* * *$ p_value $<0.001$.

\section{Discussion}

Regarding the first objective of our study, the first significant result that we find is that being a woman is associated with a higher use of mental health services. This finding is consistent with previous studies that found that gender is a predicting factor of service use $\mathrm{e}^{1-3}$. When assessing hospital admissions, the second objective, we found some interesting results: men have a higher risk of a first hospitalisation and, in addition, the length of admissions is longer for them. On the other hand, in the admitted patients group, the number of women is actu- ally higher. We have not found any other study that analyses hospitalisation using gender as the principal variable. Nevertheless, most studies that included such a variable when analysing patterns of hospital admissions also found that men are at higher risk of hospitalisation ${ }^{12,13}$. Also, the hospitalizations are specially important in patiens with more severe diagnoses such as schizophrenia which could explain this result.

Here we discuss the results related to the attended prevalence analysis as well as those related to the use of hospital care services, in both cases distinction by diagnosis is made. 
In the group of patients diagnosed with substance use we found a higher number of males. This result is consistent with previous data showing that substance abuse is more frequent in men than in women ${ }^{14}$ although we do not find any gender differences in the risk, the number of admissions or the length of admissions related to this disorder.

We found more men in the group diagnosed with schizophrenia, and this is in line with results showing that men have a higher risk of developing schizophrenia ${ }^{15}$, although this remains quite a controversial subject. Some studies assess psychotic disorders without distinguishing schizophrenia from other psychotic disorders and conclude that a higher number of women use mental health services than men ${ }^{16,17}$. When making such a distinction, we have found that prevalence of schizophrenia in men is higher than the prevalence in women, whereas other psychotic disorders show an inverted prevalence with respect to gender. We found that in the total sample of patients with schizophrenia, men have a higher probability of being admitted while there are no differences in the number of admitted patients and in the length of hospitalisations. Similar results have been described previously ${ }^{18,19}$.

The finding that there are more women in the group diagnosed with unipolar depressive disorders is consistent with most studies $^{5,6}$. However, we found that the risk of a first admission in men due to this diagnosis is higher than that for women. This finding may be explained by the fact that women consult more for less severe matters, whereas men are more often hospitalised on account of presenting more severe conditions ${ }^{7}$. Furthermore, as previously mentioned, among the group of admitted patients the number of women is actually higher, as also demonstrated by most articles on this matter which show worse prognosis in women ${ }^{20}$.
In the group of patients diagnosed with bipolar disorder, we found more women. Other studies assessing this issue find contradictory results ${ }^{21}$. According to Schaffer ${ }^{22}$, a possible explanation would be that patients experiencing depressive symptoms may be more likely to seek treatment than those with manic symptoms, especially if they are mild, and most data show that women with bipolar disorder suffer more depressive episodes than $m^{23}$. On the other hand, we did not find any gender differences in risk, or the number or length of admissions. This might be explained by the possibility that men may be admitted due to manic and women to depressive episodes.

In the group of patients diagnosed with anxiety disorders, except for OCD and social phobia, there are more females. This finding is also consistent with most studies which have assessed this issue and with the data for the general population ${ }^{5}$. As for hospitalisations, there are no relevant differences in the risk, or the number or length of admissions. It is important to bear in mind that we are referring to few analysed cases, since fewer people are admitted for this disorder. As for personality disorders, when assessing gender differences, the most studied is borderline personality disorder. We found more women in the group of patients diagnosed with this disorder. Community studies offer contradictory data, but other studies, both epidemiological and of clinical samples, find that such risk is higher in women than in men ${ }^{24,25}$. A recent study ${ }^{26}$ has not found any differences in the use of mental health services between men and women with borderline personality disorder. However, the study sample is smaller than ours and, as it is a clinical trial, it has different clinical characteristics The gender differences that we have found in other personality disorders coincide with those of the general popula- 
$\operatorname{tion}^{27}$. As for hospitalisations, we have not found any gender differences for any personality disorder.

Gender differences have been clearly found in eating disorders, which are more frequent in women, and in sexual and impulse-control disorders, which are more frequent in men. These findings are consistent with general population data ${ }^{28}$.

We would like to outline some strengths of our study: As far as we know, this is the first study assessing gender differences in attended prevalence in specialised mental health services. The data were collected from clinical records in a computerised registry and we have analysed the total attended population over 5 years in a large section of the Barcelona metropolitan area representing 800,000 people. This is a substantial section of the population of Catalonia and provided a sample of 65,465 patients. Results from this study give us an overview of the type of care men and women who are treated in mental health are receiving. This is a first descriptive approach to the use of mental health services according to gender. In forward studies, it would be interesting to assess as well the different interventions according diagnosis and gender. The results of these studies may be useful for planning mental health services and care programmes, therefore providing better care to people who have a mental disorder according to their gender.

\section{Limitations}

Our data could be biased in favour of women, as women seek more help from specialised health services.

Our data only account for public mental health services, although it should be emphasised that the public healthcare system is the most frequently used health service in Spain, especially for people who suffer from severe mental disorders.
Admission rates do not directly represent clinical need or morbidity differences, only the use of existing mental health services.

Given that our data are extracted solely from clinical records, many of the diagnoses are not made by means of a structured clinical interview. When there are more that one diagnosis, we have included the principal diagnosis according to the clinical records

Some variables of interest that could also affect the use of services such as, among others, ethnicity or education level, were found to be incomplete for a high percentage of patients. This is probably due to factors involved in the introduction and administration of the new computerised clinical history system by mental health professionals.

\section{Conclusion}

In summary, women have a higher attended prevalence of mental disorders than men. In the total sample, women have a higher number of hospitalisations although men have a higher risk of a first hospitalisation and their stays prove to be longer. When taking diagnosis into account, gender differences are greater in attended prevalence than in number and length of hospitalisations.

\section{Acknowledgements}

This study was supported by a research grant from the Instituto de Salud Carlos III, Ministerio de Sanidad y Consumo, Spain (PI06/90233).

Raquel Iniesta was supported by a research grant from the Instituto de Salud Carlos III (CA08/00151). 
David Suarez was supported by a research grant from both the Instituto de Salud Carlos III, Ministerio de Sanidad y Consumo, Spain and the Departament de Salut, Generalitat de Catalunya (FIS ECA07/041).

\section{References}

1. Alonso J, Angermeyer MC, Bernert S, Bruffaerts R, Brugha TS, Bryson $\mathrm{H}$, et al. Use of mental health services in Europe: results from the European Study of the Epidemiology of Mental Disorders (ESEMeD) project. Acta Psychiatr Scand 2004; Suppl 109(420): 47-54.

2. Rhodes AE, Goering PN, To T, Williams JI. Gender and outpatient mental health service use. Soc Sci Med 2002; 54(1): 1-10.

3. Frayne SM, Yu W, Yano EM, Ananth L, Iqbal S, Thrailkill A, et al. Gender and use of care: planning for tomorrow's Veterans Health Administration. J Womens Health (Larchmt) 2007; 16(8): 1188-1199.

4. Alonso J, Angermeyer MC, Bernert S, Bruffaerts R, Brugha TS, Bryson H, et al. Prevalence of mental disorders in Europe: results from the European Study of the Epidemiology of Mental Disorders (ESEMeD) project. Acta Psychiatr Scand 2004; Suppl 109(420): 21-27.

5. Bijl RV, Ravelli A, van Zessen G. Prevalence of psychiatric disorder in the general population: results of The Netherlands Mental Health Survey and Incidence Study (NEMESIS). Soc Psychiatry Psychiatr Epidemiol 1998; 33(12): 587-595.

6. Kessler RC, McGonagle KA, Zhao S, Nelson CB, Hughes M, Eshleman S, et al. Lifetime and 12-month prevalence of DSM-III-R psychiatric disorders in the United States. Results from the National Comorbidity Survey. Arch Gen Psychiatry 1994; 51(1): 8-19.

7. Lisansky ES. Health Care Provision for Men and Women. In: Seeman MV, editor. Gender and Psychopathology. Washington: American Psychiatric Press; 1995. p. $359-376$

8. Queenan RA, Beauregard L. Diseases that are more prevalent in women. In: Haseltine FP, Jacobson BG, editors. Women's Health Research: A medical and policy primer. Washington: American Psychiatric Press; 1997. p. 131-158.

9. Kessler RC, Brown RL, Broman CL. Sex differences in psychiatric help-seeking: evidence from four large-scale surveys. J Health Soc Behav 1981; 22(1): 49-64.
10. Leaf PJ, Bruce ML. Gender differences in the use of mental health-related services: a re-examination. J Health Soc Behav 1987; 28(2): 171-183.

11. Navarro A, Utzet F, Puig P, Caminal J, Martín M. La distribución binomial negativa frente a la de Poisson en el análisis de fenómenos recurrentes. Gac Sanit 2001; 15 (5): 447-452.

12. Thompson A, Shaw M, Harrison G, Verne J, Ho D, Gunnell D. Patterns of hospital admission for adult psychiatric illness in England: analysis of Hospital Episode Statistics Data. Br J Psychiatry 2004; 185: 334-341.

13. Smith P, Sheldon TA, Martin S. An index of need for psychiatric services based on in-patient utilisation. Br J Psychiatry 1996; 169: 308-316.

14. Anthony JC, Warner LA, Kessler RC. Comparative epidemiology of dependence on tobacco, alcohol, controlled substances and inhalants: Basic findings from the National Comorbidity Survey. Exp Clin Psychopharmacol 1994; 2(3): 244-268.

15. Aleman A, Kahn RS, Selten JP. Sex differences in the risk of schizophrenia: evidence from meta-analysis. Arch Gen Psychiatry 2003; 60(6): 565-571.

16. Dixon L, Lyles A, Smith C, Hoch JS, Fahey M, Postrado L, et al. Use and Costs of Ambulatory Care Services Among Medicare Enrollees With Schizophrenia. Psychiatr Serv 2001; 52: 786-792.

17. Lindamer LA, Bailey A, Hawthorne W, Folsom DP, Gilmer TP, Garcia P, et al. Gender differences in characteristics and service use of public mental health patients with schizophrenia. Psychiatr Serv 2003; 54: 1407-1409.

18. Usall J, Ochoa S, Araya S, Márquez M, NEDES group. Gender differences and outcome in schizophrenia: a 2-year follow-up study in a large community sample. Eur Psychiatry 2003; 18: 282-284.

19. Test MA, Burke SS, Wallisch LS. Gender differences of young adults with schizophrenic disorders in community care. Schizophr Bull 1990; 16(2): 331-344.

20. Kornstein SG, Schatzberg AF, Thase ME, Yonkers KA, McCullough JP, Keitner GI, et al. Gender differences in chronic major and double depression. J Affect Disord 2000; 60: 1-11.

21. Hendrick V, Altshuler LL, Gitlin MJ, Delrahim S, Hammen C. Gender and bipolar illness. J Clin Psychiatry 2000; 61(5): 393-396.

22. Schaffer A, Cairney J, Cheung AH, Veldhuizen S, Levitt AJ. Use of treatment services and pharmacotherapy for bipolar disorder in a general population-based mental health survey. J Clin Psychiatry 2006; 67(3): 386-393. 
23. Kupfer DJ, Frank E, Grochocinski VJ, Cluss PA, Houck PR, Stapf DA. Demographic and clínical characteristics of individuals in a bipolar disorder case registry. $\mathrm{J}$ Clin Psychiatry 2002; 63(2): 120-125.

24. Swartz M, Blazer D, George L, Winfield I. Estimating the prevalence of borderline personality disorder in the community. J Personal Disord 1999; 4: 257-272.

25. Akhtar S, Byrne JP, Doghramji K. The demographic profile of borderline disorder. J Clin Psychiatry 1986; 47 : 196-198.

26. McCormick B, Blue N, Hansel R, Franklin JA, St John D, Pfohl B, et al. Relationship of sex symptom severity, psychiatric comorbidity, and health care utilization in 163 subjects with borderline personality disorder. Compr Psychiatry 2007; 48: 406-412.

27. Hensley PL, Nurnberg HG. Personality disorders. In: Kornstein SG, Clayton AH, editors. Women's mental health: A comprehensive textbook. New York: The Guilford Press; 2002. p. 323-343.

28. Powers PS. Eating disorders. In: Kornstein SG, Clayton AH, editors. Women's mental health: A comprehensive textbook. New York: The Guilford Press; 2002. p. 244-262.

Author for correspondence:

Judith Usall

Parc Sanitari Sant Joan de Déu

C/ Antoni Pujades, 42

08830 Sant Boi de Llobregat. Barcelona

Telf +34936406350

Fax +34936305319

E-mail: jusall@pssjd.org 